\title{
Assessment of Contralateral Biopsy Technique for Improving Tissue Changes in Patients with Tongue Malignancy
}

\author{
Nawres Alhatab ${ }^{1 *} \mathbb{D}$, Muntathar Muhsen Abusanna ${ }^{2} \mathbb{D}$, Haydar Salih $^{3} \mathbb{D}$ \\ ${ }^{1}$ Department of Surgery, College of Dentistry, University of Al-Ameed, Karbala, Iraq; ${ }^{2}$ Department of Oral and Maxillofacial \\ Surgery, College of Dentistry, University of Al-Ameed, Karbala, Iraq; ${ }^{3}$ Department of Surgery, College of Dentistry, Al-Mashreq \\ University, Baghdad, Iraq
}

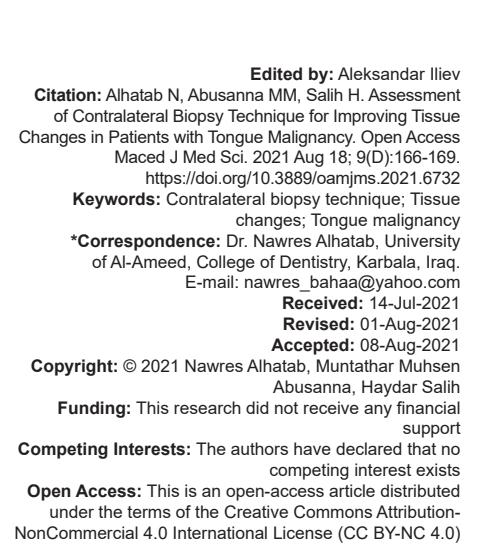

\section{Abstract}

BACKGROUND: Serious health problems in the current study are carcinoma of oral cavity (the buccal squamous cell malignancy) that leads to increase death rate in community. Oral cancer leads to high mortality and serious disorder in spite of low occurrence than other types of malignancy.

AIM: Histologically evaluate the copy biopsy occupied from clinically detecting mucosa at consistent contralatera anatomical place to the main lesion in patients recognized with tongue squamous cell carcinoma (SCC).

METHODS: Seven patients diagnosed with SCC of the tongue underwent reflect copy biopsy from clinically usual observing mucosa at consistent contralateral anatomical place to the main lesion. The reflect copy biopsy example was exposed to histopathological check.

RESULTS: Of the seven patients included, four were male and three were female, with an age range from 45 years to 64 years (median 54.5 years). One of the biopsies revealed severe dysplasia and six revealed hyperplasia of the epithelium.

CONCLUSION: Mirror image biopsy is a dependable method for the discovery of pan mucosal field alteration in patients with SCC.

\section{Introduction}

Serious health problems in the current study are carcinoma of oral cavity (the buccal squamous cell malignancy) that leads to increase death rate in community. Oral cancer leads to high mortality and serious disorder in spite of low occurrence than other types of malignancy. It consists $90 \%$ of cancer that occur in mouth and oropharynx and $10 \%$ with melanomas, sarcomas, minor malignancy of salivary gland, and metastatic tumors [1]. Cancer idea returns by numerous logical, histopathological, and molecular idea, normal epithelial tissue connects to tumor tissue and confirms by similar changes subcellular or biochemical [2]. The multiple cancers can no longer be considered rarity, but are a prevalent condition that poses an oncologic problem due to its increasing frequency. Increase in the survival rate of patients successfully treated for primary oral cancer has increased the incidence of occurrence of second primary tumor at other anatomical sites [3]. Modern theories of carcinogenesis suggest that premalignant change may occur in any area of mucous membrane exposed to a carcinogen. Hence, patients with oral cancer are at risk of developing second or multiple primary cancers within the upper aerodigestive tract [2]. The reasons for this increased incidence are multifold and the most important fact is a greater awareness of the phenomenon, which has stimulated a more extensive search for these lesions [4]. Outside inhibition, initial finding is the utmost critical element for efficacious management and persistence of oral malignancy. In adding, managing of initial phase of oral malignancy accomplished with fewer hostile procedures that can reserve vigorous organ purpose and physical presence, consequential in a healthier eminence of patients' life. Inappropriately, the common oral malignancies show progressive phase illness with spread to local lymph nodes and/or distant metastases at the time of early identification proposing that present finding procedures, based on optical checkup only, are inadequate for early tumor progress and molecular alteration [5]. The current study assesses histologically the "mirror image" biopsy occupied from the seemingly normal mucosa at consistent contralateral anatomical places in patients with solitary, unilateral clinically complete buccal squamous cell malignancy of tongue to identify any indication of field alteration in buccal mucosa. 


\section{Patients and Methods}

Seven patients with an one-sided, solitary, histologically definite buccal squamous cell carcinoma (SCC) of the tongue were selected for the study in the department of oral and maxillofacial surgery in Al-Shaheed Ghazi Al-Hariri for specialized surgeries hospital at Baghdad's medical city, from March 2015 to July 2016 out of which, four were male and three were female, with an age range from 45 years to 64 years (median 54.5 years). All patients had the primary site in the oral tongue. Five of the patients were in T2 stage and two in T3 according to the American Joint Committee on Cancer Tumor, Lymph Node, and Metastasis (AJCC TNM) staging system 2010. All the patients were in N0 stage. The histological grade of primary tumor for two patients was Grade 1 (well differentiated). Three patients have had a Grade 2 (moderately differentiated) and two have Grade 3 (poorly differentiated) SCC of tongue. Three of the patients (two males and one female) were untreated at the time of biopsy while four were treated either by surgery alone (two patients, one male and one female) or by surgery and radiotherapy (two patients, one male and one female). Two of the patients had a history of smoking, both of them were male. All the patients denied any history of alcohol consumption, chewing habits, and family history of oral SCC. None of the patients was involved in out-door occupation.

\section{Exclusion measures}

Patients have widespread midline tumors; patients have bilateral tumors, patients with metastasis, numerous buccal lesions, and patients who rejected to experience the reflect copy biopsy. Mirror image biopsy occupied from clinically usual observing mucosa at corresponding contralateral anatomical sites. The biopsy samples that were taken measured about $1^{*} 0.5 \mathrm{~cm}$ down to the submucosal layer were performed with scalpel without use of cautery and without crushing of tissues and the tongue was stabilized by the assistant by wrapping it in a gauze and holding it firmly. Three of biopsies were done under general anesthesia during ablative surgery for the tumors. The remaining were done during follow-up visits under local anesthesia, one case using nerve block, and the rest using infiltration technique. The histopathologic was informed in the later cases about type of anesthesia. The wound was closed with one $3 / 0$ silk suture. The tissues were fixed in neutral buffered formalin $10 \%$, followed by tissue processing (dehydration, cleaning and infelteration with paraffin), then the tissues were embedded with paraffin, sectioned by microtome at 5 micrometer thickness, made slides, which were stained by hematoxylin and eosin stains and finally examined with light microscope. The number approval of the ethics committee is 198 in April 25, 2015. The limitations are patient refused operation because of changes in speaking and taste and may cause restrict tongue movement during mastication.

\section{Results}

In this study, seven mirror image biopsies, which were collected from seven patients suffering from histologically confirmed oral SCC of the tongue, were included. All these patients are operated on in the Department of Oral and Maxillofacial Surgery in Al-Shaheed Ghazi Al-Hariri for Specialized Surgeries Hospital at Baghdad's Medical City, from March 2015 to July 2016. Three of the patients (two males and one female) were untreated at the time of biopsy while four were treated either by surgery alone (two patients, one male and one female) or by surgery and radiotherapy (two patients, one male and one female). Two of the patients had a history of smoking, both of them were male.

\section{Primary lesions}

All patients have had the primary lesion in the oral tongue. Four of the patients were male and three were female with an age range from 45 years to 64 years (average 54.5 years). Five of the patients were in T2 stage and two in T3 according to the AJCC TNM staging system 2010. All the patients were in NO stage. The histological grade of primary tumor for two patients was well differentiated. Three patients have had a moderately differentiated and two have poorly differentiated SCC of the tongue. Biopsies results: Six of the mirror image biopsies revealed reactive changes (hyperplasia). One of the biopsies showed severe dysplasia and the patient (male) has had a moderately differentiated SCC of T3NOMO. He had an over 20 year's history of smoking and had received adjuvant radiotherapy for the SCC of the tongue 1 year before the mirror image biopsy was taken. The six remaining cases showed hyperplasia of the epithelium. No significant association between age, gender, or pathological analysis and the probability of determining irregular histology in removed examples of clinically usual buccal mucosa established in this minor example study. As show in Table 1 and Figure 1.

\section{Table 1: Patient data and mirror image biopsy results}

\begin{tabular}{|c|c|c|c|c|c|c|}
\hline $\begin{array}{l}\text { Patient } \\
\text { No. }\end{array}$ & Age & Sex & Habit & $\begin{array}{l}\text { History of } \\
\text { radiotherapy }\end{array}$ & $\begin{array}{l}\text { Histological I } \\
\text { diagnosis }\end{array}$ & $\begin{array}{l}\text { Histology of mirror } \\
\text { image }\end{array}$ \\
\hline 1 & 45 & Male & Smoking & Positive & Mod. diff. SCC & Severe dysplasia \\
\hline 2 & 50 & Male & None & Negative & Mod. diff. SCC & Hyperplasia \\
\hline 3 & 53 & Female & None & Negative & Well-diff. SCC & Hyperplasia \\
\hline 4 & 61 & Male & Smoking & Negative & Well-diff. SCC & Hyperplasia \\
\hline 5 & 62 & Female & None & Positive & Mod. diff. SCC & Hyperplasia \\
\hline 6 & 64 & Female & None & None & Poorly diff. SCC & Hyperplasia \\
\hline 7 & 64 & Male & None & None & Poorly diff. SCC & Hyperplasia \\
\hline
\end{tabular}




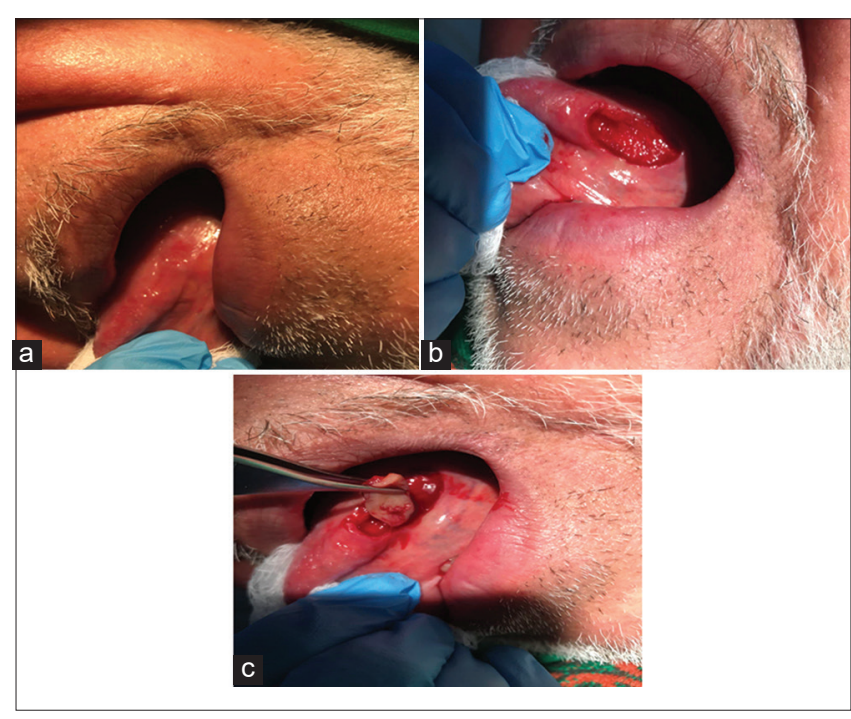

Figure 1: (a) Tongue lesion in old age patient. (b) Excisional biopsy. (c) Site of operation after lesion removal

\section{Discussion}

SCC of oral cavity rises from a sequence of stepwise hereditary variations encouraged by carcinogens, which consequently lead to scientific and tiny variations, summating to formula an invasive malignancy. The completely epithelial surface of the upper aerodigestive tract has high danger for the progress of malignant and premalignant lesions due to of numerous hereditary anomalies in the entire tissue uncovered to the similar hazard [6]. According to the multifocal concept of neoplasia, there are numerous causes (e.g., tobacco, radiation, and alcohol), which can inductee cancer progress [4], [7], [8]. An important clinical implication is that fields often remain after surgery of the primary tumor and may lead to new cancers [8]. Not only early detection and management of oral cancer are important but also equally important are early identification and management of a field, to have profound implications on cancer prevention and outcome of the treatment [8]. Finding and management should be designed at not only on the cancer but also on the field from which cancer has established [9]. Thus, advice on primary prevention by avoidance of risk factors, screening for detection of early lesions stressed on to prevent the occurrence of second primary carcinomas [4]. It is, therefore, necessary to find a reliable histopathological technique to identify highrisk subjects for the development of second primary tumor [10]. Furthermore, in one case (male), the changes were significant (severe dysplasia) and the patient has a history of smoking and radiation therapy. This agrees with many studies that stated the lateral, ventral, and the floor of buccal cavity demonstration an increased susceptibility to dysplastic modification [11], [12], [13]. It is believed that the presence of dysplasia in the oral epithelium signifies a likely progression to cancer. The consensus is that the more severe the degree of dysplasia, the greater the likelihood of progression to malignancy [14], [15], [16]. Therefore, because the majority of the patients in this study have no history of smoking, alcohol, or chewing habits, a search for other causes such as genetic, exposure to ionizing radiation, or viral infection is recommended if they showed significant changes on mirror image biopsy. Therefore, patients with single primary oral SCC can be subjected to mirror image biopsy in the presence of multiple risk factors such as increasing age, increase in the duration of exposure to carcinogen, and the male gender, to prevent the occurrence of second primary tumor and even treat the dysplastic changes if present at the earliest. This agrees with Hebbale et al., 2012 [13]. Thus, mirror image biopsy is a reliable technique in the detection of field changes of the oral mucosa in patients diagnosed with SCC. Chemotherapy has preventive effect on cancer of oral cavity mucosa and plays good role in decrease mortality and morbidity rate of this malignancy [17].

\section{Conclusion}

There is a risk to the patients with SCC to have a widespread histological field change and abnormal epithelium even in clinically normal mucosa. Mirror image biopsy is a reliable technique for the detection of pan mucosal field change in patients diagnosed with SCC. Diagnosis and management intended at not only on the tumor but also on the ground from which growth has advanced.

\section{References}

1. Pires FR, Ramos AB, Oliveira JB, Tavares AS, Luz PS Santos TC. Oral squamous cell carcinoma: Clinicopathological features from 346 cases from a single oral pathology service during an 8-year period. J Appl Oral Sci. 2013;21(5):460-7. https://doi.org/10.1590/1679-775720130317

PMid:24212993

2. González-Moles MA, Plaza-Campillo J, Ruiz-Ávila I, Herrera P, Bravo M, Gil-Montoya JA. Asymmetrical proliferative pattern loss during malignant transformation of the oral mucosa. J Oral Pathol Med. 2014;43(7):507-13. https://doi.org/10.1111/ jop. 12164

PMid:25184162

3. AIRTUM Working Group. Italian cancer figures, report 2013: Multiple tumours. Epidemiol Prev. 2013;37(4-5 Suppl 1):1-152. PMid:24259384

4. Rahman QB, Bajgai DP. Evaluation of Incidence of Premalignant and Malignant Lesions by Mirror Image Biopsy in Oral Squamous Cell Carcinoma. Cosmetol Oro Fac Surg. 2017;3:118.

5. Floriano PN, Abram T, Taylor L, Le C, Talavera H, Nguyen M, et al. Programmable bio-nanochip-based cytologic testing of oral potentially malignant disorders in Fanconi anemia. Oral Dis. 
2015;21(5):593-601. https://doi.org/10.1111/odi.12321 PMid:25662766

6. Wei ZH, Gong W, Zhou M, Chen QM. The concept of field cancerization and its clinical application. Zhonghua Kou Qiang Yi Xue Za Zhi. 2016;51(9):562-5.

PMid:27596348

7. Sabharwal R, Mahendra A, Moon NJ, Gupta P, Jain A, Gupta S. Genetically altered fields in head and neck cancer and second field tumor. South Asian J Cancer. 2014;3(3):151-3. https://doi. org/10.4103/2278-330x.136766

PMid:25136520

8. Mohan M, Jagannathan N. Oral field cancerization: An update on current concepts. Oncol Rev. 2014;8(1):244. https://doi. org/10.4081/oncol.2014.244 PMid:25992232

9. Achalli S, Babu SG, Shetty SR, Madi M. Oral field cancerization: A case report. Int J Dent Med Res. 2014:1(3):46-8.

10. Koo K, Harris R, Wiesenfeld D, Iseli TA. A role for panendoscopy? Second primary tumour in early stage squamous cell carcinoma of the oral tongue. J Laryngol Otol. 2015;129(Suppl 1):S27-31. https://doi.org/10.1017/s0022215114002989 PMid:25656280

11. Sarode SC, Sarode G, Patil S. Site-specific oral cancers are different biological entities. J Contemp Dent Pract. 2017;18(6):421-2.

PMid:28621267

12. Richter I, Alajbeg I, Boras VV, Rogulj AA, Brailo V. Mapping electrical impedance spectra of the healthy oral mucosa: A pilot study. Acta Stomatol Croat. 2015;49(4):331-9. https://doi. org/10.15644/asc49/4/9

PMid:27688418

13. Hebbale MA, Krishnappa R, Bagewadi A, Keloskar V, Kale A, Halli R. Evaluation of mirror image biopsy for incidence of multiple premalignant and malignant lesions in oral cancer a clinical study. J Indian Acad Oral Med Radiol. 2012;24(3):194-9. https://doi.org/10.5005/jp-journals-10011-1294

14. Nanayakkara PG, Dissanayaka WL, Nanayakkara BG Amaratunga EA, Tilakaratne WM. Comparison of spatula and cytobrush cytological techniques in early detection of oral malignant and premalignant lesions: A prospective and blinded study. J Oral Pathol Med. 2016;45(4):268-74. https://doi. org/10.1111/jop.12357

PMid:26403502

15. Sreedhar G, Sumalatha MN, Shukla D. An overview of the risk factors associated with multiple oral premalignant lesions with a case report of extensive field cancerization in a female patient. Biomed Pap Med Fac Univ Palacky Olomouc Czech Repub. 2015;159(2):178-83. https://doi.org/10.5507/bp.2013.092 PMid:24401899

16. Fernández PJ, Méndez-Sánchez SC, Gonzalez-Correa CA Miranda DA. Could field cancerization be interpreted as a biochemical anomaly amplification due to transformed cells? Med Hypotheses. 2016;97:107-11. https://doi.org/10.1016/j. mehy.2016.10.026

PMid:27876116

17. Tanaka T, Tanaka M, Tanaka T. Oral carcinogenesis and oral cancer chemoprevention: A review. Pathol Res Int 2011;2011:431246. https://doi.org/10.4061/2011/431246 PMid:21660266 